\title{
The effect of $\alpha$-isosaccharinic acid on the stability of and Th(IV) uptake by hardened cement paste
}

\author{
By E. Wieland*, J. Tits, J. P. Dobler and P. Spieler \\ Paul Scherrer Institut, Waste Management Laboratory, CH-5232 Villigen PSI, Switzerland
}

(Received August 22, 2001; accepted April 11, 2002)

\section{Hardened cement paste / Stability / Thorium / Sorption / Isosaccharinic acid}

\begin{abstract}
Summary. The effect of $\alpha$-isosaccharinic acid (ISA) on Th(IV) uptake by hardened cement paste (HCP) has been investigated under alkaline conditions $(\mathrm{pH}$ 13.3). Prior to performing the uptake studies the stability of HCP was determined in the presence of ISA. It was observed that the formation of Ca-ISA complexes in solution enhances portlandite solubility. The fraction of portlandite dissolved from the HCP matrix depends on the solid to liquid $(\mathrm{S} / \mathrm{L})$ ratio of the system and the ISA concentration in solution. Th(IV) uptake by $\mathrm{HCP}$ was found to be reduced above an aqueous ISA concentration of about $10^{-4} \mathrm{M}$. Reduction of Th(IV) uptake can be modelled taking into account the formation of a Th: ISA : $\mathrm{Ca}=1: 2: 1$ complex in solution. It is indicated that the formation of ternary Th(IV)-ISA complexes may be important in cement systems. The final interpretation of the data however fails due to the large uncertainties in the distribution ratios measured in the absence of ISA.
\end{abstract}

\section{Introduction}

Cementitious materials are commonly used world-wide in immobilisation strategies for the disposal of shortlived low- and intermediate-level (L/ILW) and long-lived intermediate-level (LL-ILW) radioactive wastes. Cement is an important component of the near-field of a repository because it is used to solidify and surround the waste materials and to build the engineered barrier system. The immobilisation of safety-relevant radionuclides by hardened cement paste (HCP) is an important aspect of performance assessment (PA) studies where it is considered that the solubility and interaction of radionuclides with the cement matrix determine the source term for radionuclide migration into the host rock.

The immobilisation potential of HCP originates from its selective binding properties for cations and anions present in the waste matrix, e.g., see reviews in [1-4]. Earlier studies indicate a strong uptake of Th(IV) by cementitious materials [5-7 and references therein]. Recent studies have supported this finding and, in the absence of complexing ligands, sorption values were found to be $\geq 1 \mathrm{~m}^{3} \mathrm{~kg}^{-1}[8,9]$. In addition,

\footnotetext{
*Author for correspondence (E-mail: erich.wieland@psi.ch).
}

it was shown that complexing ligands present in the cement pore water, namely products of cellulose degradation and cement additives, may exert an effect on Th(IV) uptake by cementitious and naturally occurring solid materials [8-12]. The objectives of the experiments described here were to investigate the effect of $\alpha$-isosaccharinic acid (ISA) on the stability of HCP and on Th(IV) uptake by HCP under conditions relevant to the near-field of a repository for radioactive waste. ISA has been reported to be the main product in the degradation of cellulosic material under alkaline conditions $[13,14]$, and moreover, it forms stable complexes namely with tri- and tetravalent nuclides $[15,16]$. Th(IV) is often chosen to be representative of a major group of the safety-relevant radionuclides present in the waste matrix, i.e., the tetravalent actinides.

\section{Materials and methods}

A crushed material prepared from hardened cement paste (HCP) was employed in the experiments. Commercial sulphate-resisting cement (Type CPA 55 HTS, Lafarge, France), denoted as HTS (Haute Teneur en Silice), was used to manufacture the cement paste as described by Sarott et al. [17]. The crushed material was prepared from bulk samples by grinding in a mortar under $\mathrm{CO}_{2}$ free conditions and sieving the material to collect the size fractions $<70 \mu \mathrm{m}$. The $\mathrm{N}_{2}$-BET surface area of the powder was determined to be $46 \pm 4 \mathrm{~m}^{2} \mathrm{~g}^{-1}$.

Synthesis and analytical determination of $\alpha$-ISA in alkaline solutions are described in detail by Van Loon and Glaus [23]. For this work, ISA stock solutions of $0.1 \mathrm{M}$ and $10^{-3} \mathrm{M}$ were prepared and diluted to obtain the required initial concentrations in the experiments. Aqueous ISA concentrations were estimated based on previously published sorption isotherms for ISA $[22,23]$ and checked on a few samples.

Prior to the uptake studies, stability tests with HCP were carried out for the relevant experimental system, i.e., HCP powder in contact with artificial cement pore water (ACW) containing ISA. For this, HCP powder was immersed in ACW with increasing ISA concentrations at a solid to liquid $(\mathrm{S} / \mathrm{L})$ ratio of $1.25 \times 10^{-2} \mathrm{~kg} \mathrm{~L}^{-1}$. The suspensions were equilibrated for at least 30 days. Kinetic tests showed that 30 days was the minimum time required to Brought to you by | Lib4RI Eawag-Empa 
reach equilibrium in stability tests [19]. Thereafter, solid and liquid phases were separated by centrifugation $(60 \mathrm{~min}$ at $95000 \mathrm{~g}$ ). Aliquots were withdrawn from the supernatant, acidified and analysed by ICP-OES for the important cement-derived elements $\mathrm{Na}, \mathrm{K}, \mathrm{Ca}, \mathrm{Al}, \mathrm{Si}$ and $\mathrm{S}$.

For the uptake studies, cement suspensions were prepared by contacting HCP powder with ACW. The preparation of the ACW is described in an earlier publication [9]. The resulting $\mathrm{pH}$ was 13.3 , ionic strength was $0.3 \mathrm{M}$ and the total carbonate concentration was at a level corresponding to saturation with respect to $\mathrm{CaCO}_{3}\left(1.2 \times 10^{-4} \mathrm{M}\right)$. Batch-type uptake studies were conducted using the method reported by Wieland et al. [9]. In contrast to the earlier study, the $\mathrm{S} / \mathrm{L}$ ratios of the suspensions were increased to $10^{-4} \mathrm{~kg} \mathrm{~L}^{-1}$ and $5 \times 10^{-3} \mathrm{~kg} \mathrm{~L}^{-1}$ to minimise possible uncertainties associated with the very low solid content used in the previous experiments. The cement suspensions were pre-equilibrated for at least 14 days prior to adding the radiotracer.

Partitioning of Th(IV) between the solid and liquid phase was determined using ${ }^{228} \mathrm{Th}$ tracer $\left(\gamma\right.$-emitter, $\left.t_{1 / 2}=1.91 \mathrm{y}\right)$ purchased from CIS Medipro AG, Teufen, Switzerland and carrier-free ${ }^{234} \mathrm{Th}$ tracer $\left(\beta\right.$-emitter, $\left.t_{1 / 2}=24.1 \mathrm{~d}\right)$ prepared according to a slightly modified version of the ion exchange method described by Dyrssen [20]. Activity measurements were carried out using a Packard Cobra 5003 auto gamma counter for ${ }^{228} \mathrm{Th}$ assay, and a Canberra Packard Tri-carb $2250 \mathrm{CA}$ liquid scintillation counter for ${ }^{234} \mathrm{Th}$ assay. Prior to ${ }^{228} \mathrm{Th}$ activity measurements, suspensions and solutions were stored for at least one month to allow secular equilibrium with the daughters to be established. Note that Th(IV) tracer solutions were found to be stable up to total concentrations of approximately $10^{-9} \mathrm{M}$ [12]. In this work $\mathrm{Th}(\mathrm{IV})$ concentrations used were $\leq 10^{-10} \mathrm{M}$.

The partitioning of the tracers was quantified in terms of a distribution ratio ( $R_{\mathrm{d}}$ value), which is defined as follows:

$$
\begin{aligned}
R_{\mathrm{d}} & =\frac{A_{\mathrm{s}}}{A_{1}}=\left(\frac{A_{\text {input }}-A_{\text {wall }}-A_{1}}{A_{1}}\right) \cdot\left(\frac{V}{m}\right) \\
& =\left(\frac{A_{\text {susp }}-A_{1}}{A_{1}}\right) \cdot\left(\frac{V}{m}\right) \quad\left[\mathrm{m}^{3} \mathrm{~kg}^{-1}\right] .
\end{aligned}
$$

$A_{\mathrm{s}}$ and $A_{1}$ denote radionuclide activities measured on the solid and in solution, respectively, at equilibrium in counts per minute (cpm) $\left[\mathrm{cpm} \mathrm{kg}{ }^{-1}\right.$ and $\left.\mathrm{cpm} \mathrm{m}^{-3}\right] . V$ and $m$ denote the volume of ACW $\left[\mathrm{m}^{3}\right]$ and the mass of HCP $[\mathrm{kg}]$, respectively. The difference between total activity of the sus- pension $\left(A_{\text {susp }}\right)$ and the activity of the supernatant solution after centrifugation $\left(A_{1}\right)$ was taken as measure of the tracer activity on the solid. $A_{\text {susp }}$ is the total activity of the suspension prior to separating solid and liquid phases $\left[\mathrm{cpm} \mathrm{m}^{-3}\right]$. $A_{\text {input }}$ and $A_{\text {wall }}$ denote the activities [cpm m${ }^{-3}$ ] added to the system and sorbed on the walls of the polyallomere centrifuge tubes, which were used for the experiments. In the case of ${ }^{228} \mathrm{Th} A_{\text {susp }}$ was determined directly in aliquots taken from the cement suspension. In the case of ${ }^{234} \mathrm{Th}$, however, $A_{\text {wall }}$ was determined separately as follows: At the end of each uptake experiment solid and liquid phases were discarded, the tubes rinsed with water and filled with $1 \mathrm{M} \mathrm{HCl}$ to desorb Th(IV) from the walls. ${ }^{234} \mathrm{Th}$ activities were determined in the acid extracts after equilibration for one day.

\section{Results}

\section{Stability of HCP}

Recent studies by Vercammen et al. [21] showed that $\mathrm{Ca}$ may form complexes with ISA under alkaline conditions. Thus, Ca complexation by ISA was suggested to promote the leaching of $\mathrm{Ca}$ from $\mathrm{Ca}$ containing phases in the $\mathrm{HCP}$ matrix. Measuring the $\mathrm{Ca}$ concentration in $\mathrm{ACW}$ at increasing ISA concentrations allowed us to determine the stability of HCP. Fig. 1 shows that $\mathrm{Ca}$ concentrations were enhanced in the HCP suspensions at aqueous ISA concentrations above about $10^{-3} \mathrm{M}$ under the given experimental conditions $\left(\mathrm{S} / \mathrm{L}\right.$ ratio $\left.=1.25 \times 10^{-2} \mathrm{~kg} \mathrm{~L}^{-1}\right)$. This indicates dissolution of $\mathrm{Ca}$ containing cement phases in the presence of ISA. Further analysis of the data showed that the effect of ISA on the total Ca concentration in solution $\left([\mathrm{Ca}]_{\mathrm{tot}}^{\mathrm{sol}}\right)$ can be modelled assuming portlandite dissolution and Ca-ISA complex formation:

$$
\begin{aligned}
{[\mathrm{Ca}]_{\mathrm{tot}}^{\mathrm{sol}}=\frac{K_{\mathrm{S}}\left[\mathrm{H}^{+}\right]^{2}}{\left(K_{\mathrm{W}}\right)^{2}}(} & 1+\frac{K_{11}}{\left[\mathrm{H}^{+}\right]}+\left[\mathrm{ISA}^{-}\right] \\
& \left.\times\left(\frac{K_{\mathrm{CaISA}^{0}}}{\left[\mathrm{H}^{+}\right]}+K_{\mathrm{CaISA}^{+}}\right)\right)[\mathrm{M}] .
\end{aligned}
$$

Calculations were based on the chemical equilibria and thermodynamic constants listed in Table 1. Fig. 1 reveals good agreement between experimental data and thermodynamic calculations. The difference between model calculations and experimental data is attributed to uncertainties associated with the thermodynamic constants and the experimental data.

\begin{tabular}{|c|c|c|c|}
\hline Solids & $\begin{array}{l}\log K_{\mathrm{S}} \\
(I=0.3)^{a}\end{array}$ & Chemical equilibrium & Reference \\
\hline $\begin{array}{l}\mathrm{CaCO}_{3} \\
\mathrm{Ca}(\mathrm{OH})_{2}\end{array}$ & $\begin{array}{l}-7.17 \\
-4.31\end{array}$ & $\begin{array}{l}\mathrm{CaCO} C_{3} \Leftrightarrow \mathrm{Ca}^{2+}+\mathrm{CO}_{3}{ }^{2-} \\
\mathrm{Ca}(\mathrm{OH})_{2} \Leftrightarrow \mathrm{Ca}^{2+}+2 \mathrm{OH}^{-}\end{array}$ & $\begin{array}{l}\text { Hummel et al. [26] } \\
\text { Hummel et al. [26] }\end{array}$ \\
\hline Species & $\begin{array}{l}\log K \\
(I=0.3)^{a}\end{array}$ & Chemical equilibrium & Reference \\
\hline $\begin{array}{l}\mathrm{CaOH}^{+} \\
\mathrm{Ca}(\text { ISA) } \\
\\
\mathrm{Ca}(\text { ISA) }\end{array}$ & $\begin{array}{r}-13.07 \\
-10.99 \\
1.12\end{array}$ & $\begin{array}{l}\mathrm{Ca}^{2+}+\mathrm{H}_{2} \mathrm{O} \Leftrightarrow \mathrm{CaOH}^{+}+\mathrm{H}^{+} \\
\mathrm{Ca}^{2+}+\mathrm{ISA}^{-} \Leftrightarrow \mathrm{Ca}\left(\text { ISA }-\mathrm{I}^{0}\right)^{0}+\mathrm{H}^{+} \\
\mathrm{Ca}^{2+}+\mathrm{ISA}^{-} \Leftrightarrow \mathrm{Ca}(\text { ISA })^{+}\end{array}$ & $\begin{array}{l}\text { Hummel et al. [26] } \\
\text { Vercammen } \text { et al. }[21] \\
\text { Vercammen } \text { et al. }[21]\end{array}$ \\
\hline
\end{tabular}

Table 1. Conditional thermodynamic constants for solubility and speciation calulations $\left(I=0.3, T=25^{\circ} \mathrm{C}\right)$. a: The thermodynamic constants $\left(\log K^{0}\right.$ and $\left.\log K_{\mathrm{s}, 0}^{0}\right)$ were taken from the references listed in the table and corrected for ionic strength $I=0.3 \mathrm{M}$ using the Davies equation. 


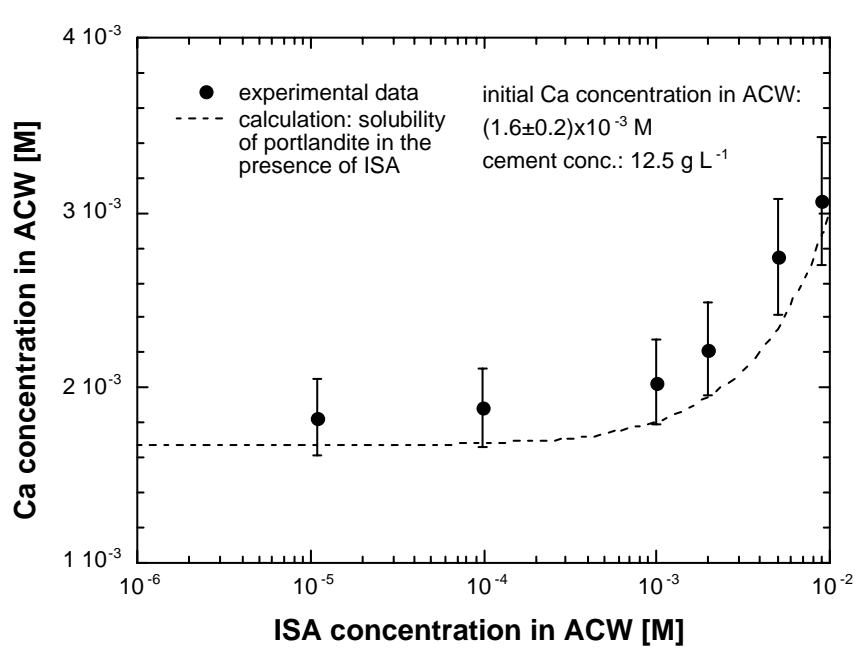

Fig. 1. Dependence of the Ca concentration in ACW on the aqueous ISA concentration. Predictions are made on the assumption that the free $\mathrm{Ca}$ concentration is controlled by portlandite solubility. Ca speciation at $\mathrm{pH}=13.3$ is dominated by the first hydrolysis product and the formation of Ca-ISA complexes.

\section{Uptake of Th(IV) by HCP in the absence and presence of ISA}

Complex formation in solution and uptake of Th(IV) by $\mathrm{HCP}$ are considered to be competing reactions. In the absence of ISA and under the given experimental conditions, i.e., high $\mathrm{pH}$ and low $\mathrm{CO}_{3}{ }^{2-}$ and $\mathrm{Cl}^{-}$concentrations, $\mathrm{OH}^{-}$is the only relevant complexing ligand in solution. In general, hydrolysis reactions of a metal cation $\mathrm{M}^{z+}$ are given by:

$$
\mathrm{M}^{z+}+m \mathrm{OH}^{-} \Leftrightarrow \mathrm{M}(\mathrm{OH})_{m}{ }^{z-m} \text { and } \beta_{m}^{\mathrm{OH}}=\frac{\left[\mathrm{M}(\mathrm{OH})_{m}{ }^{2-m}\right]}{\left[\mathrm{M}^{z+}\right]\left[\mathrm{OH}^{-}\right]^{m}} .
$$

With this, the distribution ratio defined in Eq. (1) can be rewritten as:

$$
R_{\mathrm{d}}^{0}=\frac{\left\{\mathrm{M}_{\mathrm{s}}\right\}}{\left[\mathrm{M}^{z+}\right]\left(1+\sum_{m} \beta_{m}^{\mathrm{OH}} \cdot\left[\mathrm{OH}^{-}\right]^{m}\right)} \quad\left[\mathrm{m}^{3} \mathrm{~kg}^{-1}\right] .
$$

$\left\{\mathrm{M}_{\mathrm{s}}\right\}$ denotes the concentration of Th(IV) sorbed [mol kg-1]; $\left[\mathrm{M}^{z+}\right]$ is the free metal concentration in solution; $R_{\mathrm{d}}^{0}$ denotes the distribution ratio determined in the absence of ISA.

Experimental data on the effect of ISA on Th(IV) uptake by HCP are shown in Fig. 2. Th(IV) uptake was found to be dependent on the aqueous ISA concentration. Reduction of the Th(IV) uptake in the presence of ISA is attributed to the formation of Th(IV)-ISA complexes in solution. In an earlier study the effect of ISA on $\mathrm{Th}(\mathrm{IV})$ and $\mathrm{Eu}(\mathrm{III})$ uptake by cement has already been suggested [9]. Nevertheless, interpretation of the data at that time was limited due to missing thermodynamic information on Th(IV)-ISA complex formation. According to Vercammen et al. [16] a Th: ISA : $\mathrm{Ca}=1: 2: 1$ solution complex is formed under the conditions relevant to this study. Consideration of the stabilising effect of $\mathrm{Ca}^{2+}$ on Th(IV)-ISA complexes is necessary based on the experimental results published by these authors $[15,16]$.

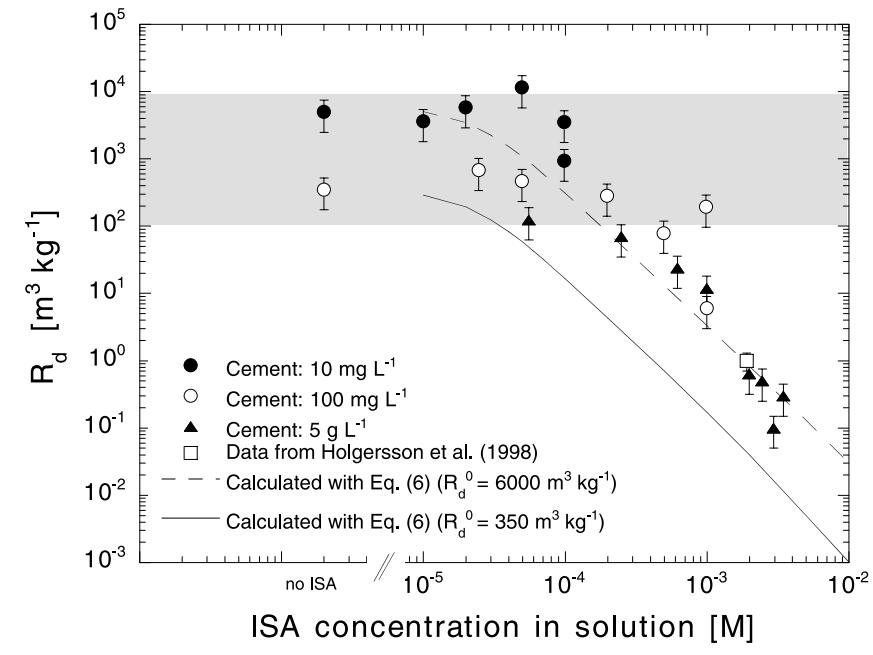

Fig. 2. Effect of $\alpha$-isosaccharinic acid on Th(IV) uptake by cement. Measurements were carried out on cement systems with different S/L ratios. Predictions are based on Eq. (6) assuming $R_{\mathrm{d}}^{0}=350 \mathrm{~m}^{3} \mathrm{~kg}^{-1}$ and $R_{\mathrm{d}}^{0}=6000 \mathrm{~m}^{3} \mathrm{~kg}^{-1}$.

The reaction schemes proposed by Vercammen et al. [16] and by Tits et al. [12] can be applied to cement systems. Taking into account Th(IV)-ISA complex formation in solution, the distribution ratio $R_{\mathrm{d}}$ can be written as:

$$
R_{\mathrm{d}}=\frac{\left\{{ }^{*} \mathrm{M}_{\mathrm{s}}\right\}}{\left[{ }^{*} \mathrm{M}^{z+}\right]\left(1+\sum_{m} \beta_{m}^{\mathrm{OH}} \cdot[\mathrm{OH}]^{m}+\beta_{\mathrm{ThISA}} \cdot \frac{\left[\mathrm{H}_{4}\left[\mathrm{SA}^{-}\right]^{2}\left[\mathrm{Ca}^{2+}\right]\right.}{\left[\mathrm{H}^{+}\right]^{4}}\right)}
$$

Note that the concentrations of free and sorbed metal species are different in the absence and presence of ISA. However, assuming linear sorption for which $\left\{\mathrm{M}_{\mathrm{s}}\right\} /\left[\mathrm{M}^{\mathrm{z}}\right]=$ $\left\{{ }^{*} \mathrm{M}_{\mathrm{s}}\right\} /\left[{ }^{*} \mathrm{M}^{z+}\right]$ holds, Eqs. (2) and (3) can be combined and re-written in the logarithmic form to yield:

$$
\begin{array}{r}
\log R_{\mathrm{d}}=\log R_{\mathrm{d}}^{0}-\log \left(1+\frac{\beta_{\text {ThISA }}\left[\mathrm{Ca}^{2+}\right]}{A\left[\mathrm{H}^{+}\right]^{4}}\left[\mathrm{H}_{4} \mathrm{ISA}^{-}\right]^{2}\right) \\
{\left[\mathrm{m}^{3} \mathrm{~kg}^{-1}\right],}
\end{array}
$$

where

$$
A \cong 1+\beta_{4}^{\mathrm{OH}}\left[\mathrm{OH}^{-}\right]^{4} .
$$

Fig. 2 shows predictions of the effect of ISA on Th(IV) uptake. The relevant reaction stoichiometries of Th(IV)ISA complex formation and Th(IV) hydrolysis including the corresponding thermodynamic constants are listed in Table 2. Note that the distribution ratios are plotted as a function of the aqueous ISA concentration. The latter was estimated based on the total ISA concentration added and published sorption isotherms for ISA [22,23]. Fig. 2 reveals that predictions of the effect of ISA based on Eq. (6) and interpretation of the data are dependent on the $R_{\mathrm{d}}^{0}$ value, i.e., the distribution ratio of Th(IV) determined in the absence of ISA. The following discussion will be based on predictions made using $R_{\mathrm{d}}^{0}=$ $350 \mathrm{~m}^{3} \mathrm{~kg}^{-1}$ (solid line) and $R_{\mathrm{d}}^{0}=6000 \mathrm{~m}^{3} \mathrm{~kg}^{-1}$ (broken line). 
Table 2. Relevant conditional complexation constants for aqueous Th(IV) complexes under alkaline conditions $(I=0.3$, $T=25^{\circ} \mathrm{C}$ ).

\begin{tabular}{lcc}
\hline Chemical equilibrium & $\begin{array}{c}\log \beta \\
(I=0.3)^{a}\end{array}$ & Reference \\
\hline $\mathrm{Th}^{4+}+4 \mathrm{OH}^{-} \Leftrightarrow \mathrm{Th}(\mathrm{OH})_{4}(\mathrm{aq})$ & 34.9 & Hummel et al. $[26]$ \\
$\mathrm{Th}^{4+}+2 \mathrm{H}_{4} \mathrm{ISA}^{-}+\mathrm{Ca}^{2+} \Leftrightarrow \mathrm{Th}\left(\mathrm{H}_{2} \mathrm{ISA}\right)_{2} \mathrm{Ca}+4 \mathrm{H}^{+}$ & $-(7.4 \pm 0.3)$ & Tits et al. [12] \\
\hline $\begin{array}{l}\text { a: The thermodynamic complexation constants } \log \beta^{0} \text { were taken from the references listed in the } \\
\text { table and corrected for ionic strength } I=0.3 \mathrm{M} \text { using the Davies equation. }\end{array}$
\end{tabular}

\section{Discussion}

Investigations of the stability of $\mathrm{HCP}$ powder in $\mathrm{ACW}$ in the presence of ISA were performed to assess changes in the chemical composition of the cement suspensions and to define appropriate experimental conditions for uptake studies. Dissolution of HCP in the presence of ISA was found to limit the "experimental window" for uptake studies. The present assessment is based on the assumption that a maximum of $20 \mathrm{wt} . \%$ of portlandite is allowed to dissolve without altering the cement matrix significantly and causing artefacts in the uptake experiments. On this assumption, a HCP loss of a maximum of $5 \mathrm{wt} \%$ can be accepted, taking into account the weight content of portlandite in the cement matrix (range 20 to $25 \mathrm{wt}$ \%). Note however that the limit is arbitrarily chosen. The effect of ISA on the $\mathrm{Ca}$ concentration in HCP suspensions can be predicted assuming portlandite solubility and the formation of aqueous Ca-ISA complexes (Fig. 1). This effect can be quantified taking into account the quantity of HCP in the system and the total ISA concentration added. Based on the above assumptions, it was estimated that the aqueous ISA concentration was allowed to be at most $10^{-3} \mathrm{M}$ at a $\mathrm{S} / \mathrm{L}$ ratio of $10^{-4} \mathrm{~kg} \mathrm{~L}^{-1}$ and at most $5 \times 10^{-2} \mathrm{M}$ at a $\mathrm{S} / \mathrm{L}$ ratio of $5 \times 10^{-3} \mathrm{~kg} \mathrm{~L}^{-1}$. Note that the maximum ISA concentration in the cement pore water at $\mathrm{pH} 13.3$ was determined to be $4.4 \times 10^{-2} \mathrm{M}$ [24]. Based on these findings, maximum ISA concentrations have been considered in the uptake experiments according to the $\mathrm{S} / \mathrm{L}$ ratios and the free ISA concentrations of the suspensions.

Fast kinetics was found to be characteristic for Th(IV) uptake by HCP [9]. The earlier study showed that equilibrium was reached within less than two days in the presence and absence of ISA. Studies on Th(IV) uptake by CSH phases corroborate fast uptake kinetics in cementitious systems $[11,25]$. Note that $\mathrm{CSH}$ phases are expected to be important sorbing phases for Th(IV) in the cement matrix, primarily due to their abundance $(\sim 50 \mathrm{wt} . \%)$ and their high sorption capacity. In all cases $R_{\mathrm{d}}$ values $\geq 100 \mathrm{~m}^{3} \mathrm{~kg}^{-1}$ have been reported indicating strong uptake of Th(IV) by HCP at $\mathrm{pH}$ 13.3.

The influence of $\alpha$-ISA on Th(IV) uptake by feldspar was recently investigated by Van Loon and Glaus [23] and Van Loon et al. [10]. Tits et al. [12] studied the effect of $\alpha$-ISA on Th(IV) uptake by calcite. In all these studies a significant effect of ISA on Th(IV) uptake was observed above $[\mathrm{ISA}]_{\mathrm{aq}} \sim 10^{-5} \mathrm{M}$. In this study, however, a reduction in the Th(IV) uptake by HCP was found to be significant only above [ISA] $]_{\mathrm{aq}} \sim 10^{-4} \mathrm{M}$, taking into account uncertainties on the distribution ratios in the absence of ISA (shaded area in Fig. 2). Van Loon et al. [10] and Tits et al. [12] modelled the effect of ISA on Th(IV) uptake by considering Th(IV)-ISA complex formation in solution according to the stoichiometries proposed by Vercammen et al. [16]. It is worth mentioning that the determination of the stoichiometric coefficients and the stability constants $\beta_{\text {Th-ISA }}$ is dependent on the assumptions made concerning the relevant hydrolysis products for Th(IV) at high $\mathrm{pH}$ as well as the corresponding hydrolysis constants [16]. Our data interpretation is based on the assumption that $\mathrm{Th}(\mathrm{OH})_{4}$ is the dominant hydrolysis product at $\mathrm{pH} 13.3$ and on a set of self-consistent thermodynamic constants reported by Hummel et al. [26]. With this, the stability constants, $\beta_{\text {Th-ISA }}$, for the Th(IV)-ISA complex, which were deduced from the data published by Vercammen et al. [16] and Tits et al. [12], are found to be consistent using the hydrolysis product and constant listed in Table 2, i.e., $\left(\log \beta_{\text {Th-ISA }}^{0.3}\right):-(7.4 \pm 0.1)$ [16] and $-(7.4 \pm 0.3)[12])$.

Reduction of Th(IV) uptake by HCP in the presence of ISA can be modelled using the complexation scheme previously reported $[12,16]$ and assuming $R_{\mathrm{d}}^{0}=6000 \mathrm{~m}^{3} \mathrm{~kg}^{-1}$ (dashed line). In this case, sorption reduction due to the presence of ISA can be attributed to the formation of Th(IV)-ISA complexes in solution. Note that a $R_{\mathrm{d}}^{0}$ value $\geq 1000 \mathrm{~m}^{3} \mathrm{~kg}^{-1}$ is supported from uptake measurements carried out at a $\mathrm{S} / \mathrm{L}$ ratio $=10^{-5} \mathrm{~kg} \mathrm{~L}^{-1}$ [9]. Nevertheless, the effect of ISA on $\mathrm{Th}(\mathrm{IV})$ uptake is overestimated if the distribution ratio in the absence of ISA is taken to be lower, i.e., $R_{\mathrm{d}}^{0}=350 \mathrm{~m}^{3} \mathrm{~kg}^{-1}$ (solid line in Fig. 2). A $R_{\mathrm{d}}$ value ranging from $100 \mathrm{~m}^{3} \mathrm{~kg}^{-1}$ to $1000 \mathrm{~m}^{3} \mathrm{~kg}^{-1}$ is indicated from measurements at $\mathrm{S} / \mathrm{L}$ ratios $\geq 10^{-4} \mathrm{~kg} \mathrm{~L}^{-1}$. Moreover, studies of Th(IV) uptake by CSH phases corroborate a $R_{\mathrm{d}}^{0}$ value in this range $[11,25]$. On this assumption, however, the formation of ternary Th(IV)ISA complexes at the HCP-ACW interface is necessary to explain the discrepancy between the predicted ISA effect (solid line in Fig. 2) and the experimental data. The formation of ternary Th(IV)-ISA complexes implies that aqueous Th(IV)-ISA complexes may sorb onto the HCP surface and, therefore, enhance the overall Th(IV) uptake. Note that ISA was found to strongly sorb on HCP and CSH phases [22], which certainly justifies consideration of ternary complex formation in cement systems. Nevertheless, uncertainties in the $R_{\mathrm{d}}^{0}$ value are too large to enable a final mechanistic interpretation of the ISA effect on Th(IV) uptake to be made based on the currently available data. Precise measurements of the distribution ratio for Th(IV) are needed, but constrained by the following experimental conditions: a) High activities (or concentrations, respectively) are required to reduce the sources of error caused by radio assay to a statistically acceptable level [12]. Note that Th(IV) tracer solutions are stable up to a maximum concentration of $10^{-9} \mathrm{M}$, which limits the concentration range for tracer studies. b) The very low solid concentrations required in Brought to you by | Lib4RI Eawag-Empa

Authenticated 
these experiments raises questions concerning the preparation of representative HCP samples and the stability of the material at low $\mathrm{S} / \mathrm{L}$ ratios. The reasons for the observed variations in the $R_{\mathrm{d}}^{0}$ value in the absence of ISA are unclear at present. It appears, however, that precise measurements of the distribution ratio in the absence of ISA and at S/L ratios $\leq 10^{-4} \mathrm{~kg} \mathrm{~L}^{-1}$ are needed for a more detailed interpretation of the data.

Nevertheless, the actual knowledge on the overall effect of ISA on Th(IV) uptake allows us to already assess its impact on radionuclide mobility in a cementitious near-field. A lower bound value for the distribution ratio of Th(IV) in the absence of ISA is assumed, i.e., $R_{\mathrm{d}}^{0}=100 \mathrm{~m}^{3} \mathrm{~kg}^{-1}$. With this, a reduction of Th(IV) uptake by HCP in the presence of ISA is expected only at [ISA $]_{\mathrm{aq}}>10^{-4} \mathrm{M}$ based on the experimental data displayed in Fig. 2. The ISA concentration in the pore water of the cementitious near-field was reported to depend on the amount of cellulose in the repository, the extent of degradation, the stability of ISA, the formation of sparingly soluble solids and the sorption of ISA [23]. The main process regulating the concentration of ISA in the cement pore water however is ISA sorption on HCP. For example, estimates made for the present design of the Swiss ILW repository showed that the ISA concentration in the pore water is expected to be, at a maximum, $\sim 3 \times 10^{-6} \mathrm{M}$ if the total cellulose inventory $(\sim 500 \mathrm{~kg})$ degrades and ISA is allowed to sorb on HCP [27]. The ISA concentration in the pore water is expected to be $\sim 3 \times 10^{-7} \mathrm{M}$ for a more realistic case, where only $10 \%$ of the cellulose inventory degrades and ISA sorption is allowed. The experimental data clearly indicate that no significant effect of ISA on Th(IV) uptake by HCP is anticipated at these concentration levels.

Acknowledgment. The authors would like to thank L. van Loon, M. Glaus, A. Laube and S. Stallone for providing us with $\alpha$-isosaccharinic acid and the analyses of ISA containing solutions. Valuable discussions on the topic addressed in this paper and careful review of the manuscript by M. Bradbury are gratefully acknowledged. A special thank is extended to I. Hagenlocher for her continuous interest in this work. Partial financial support was provided by the National Cooperative for the Disposal of Radioactive Waste (NAGRA), Switzerland.

\section{References}

1. Glasser, F. P.: Chemistry of cement-solidified waste forms. In: Chemistry and microstructure of solidified waste forms. (Spence, R. D., ed.) Lewis Publishers, Boca Raton (1993) pp. $1-39$.

2. Cocke, D. L., Mollah, M. Y. A.: The chemistry and leaching mechanisms of hazardous substances in cementitious solidificationstabilization systems. In: Chemistry and microstructure of solidified waste forms. (Spence, R. D., ed.) Lewis Publishers, Boca Raton (1993) pp. 187-242.

3. Bonen, D., Sarkar, S. L.: The present state-of-the-art of immobilization of hazardous heavy metals in cement-based materials. In: Advances in cement and concrete. (Grutzeck, W. M., Sarkar, S. L., eds.) American Society of Civil Engineers, New York (1994) pp. 481-493.

4. Gougar, M. L. D., Scheetz, B. E., Roy, D. M.: Ettringite and C-S-H Portland cement phases for waste ion immobilization: A review. Waste Management 16, 295 (1996).

5. Allard, B., Eliasson, L., Höglund, S., Andersson, K.: Sorption of Cs, I and actinides in concrete systems. SKB Technical Report SKB/KBS TR-84-15, SKB, Stockholm, Sweden (1984).

6. Allard, B.: Radionuclide sorption on concrete. Nagra Technical Report NTB 85-21, Wettingen, Switzerland (1985).
7. Bradbury, M. H., Sarott, F. A.: Sorption data bases for the cementitious near-field of a L/ILW repository for performance assessment. PSI Bericht 95-06, Paul Scherrer Institut, Villigen, Switzerland (1995), and Nagra Technical Report NTB 93-08, Wettingen, Switzerland (1993).

8. Holgersson, S., Albinsson, Y., Allard, B., Boren, H., Pavasars, I., Engkvist, I.: Effects of gluco-isosaccharinate on Cs, Ni, Pm and Th sorption onto, and diffusion into cement. Radiochim. Acta 82, 393 (1998).

9. Wieland, E., Tits, J., Spieler, P., Dobler, J. P.: Interaction of Eu(III) and Th(IV) with sulphate-resisting Portland cement. Mat. Res. Soc. Symp. Proc. 506, 573 (1998).

10. Van Loon, L. R., Glaus, M. A., Laube, A., Stallone, S.: Degradation of cellulosic materials under the alkaline conditions of a cementitious repository for low- and intermediate level radioactive waste. Part III: Effect of degradation products on the sorption of radonuclides on feldspar, Radiochim. Acta 86, 183 (1999).

11. Tits, J., Wieland, E., Bradbury, M. H., Dobler, J. P.: The uptake of $\mathrm{Eu}(\mathrm{III})$ and $\mathrm{Th}(\mathrm{IV})$ by cement-type minerals in the alkaline disturbed zone of a nuclear waste repository. In: Applied Mineralogy. (Rammlmair, D., Mederer, J., Oberthür, Th., Heimann, R. B., Pentinghaus, H., eds.) Balkema, Rotterdam (2000) pp. 691-694.

12. Tits, J., Wieland, E., Bradbury, M. H., Eckert, P., Schaible, A.: The uptake of $\mathrm{Eu}(\mathrm{III})$ and $\mathrm{Th}(\mathrm{IV})$ by calcite under hyperalkaline conditions: The influence of gluconic acid and $\alpha$-isosaccharinic acid. PSI Report 02-03, Paul Scherrer Institut, Villigen, Switzerland, and Nagra Technical Report NTB 02-08, Nagra, Wettingen, Switzerland (2002).

13. Glaus, M. A., Van Loon, L. R., Achatz, S., Chodura, A., Fischer, K.: Degradation of cellulosic materials under the alkaline conditions of a cementitious repository for low- and intermediate level radioactive waste. Part I: Identification of degradation products. Anal. Chim. Acta 398, 111 (1999).

14. Van Loon, L. R., Glaus, M. A., Laube, A., Stallone, S.: Degradation of cellulosic materials under the alkaline conditions of a cementitious repository for low- and intermediate level radioactive waste. Part II: Degradation kinetics. J. Environ. Polymer Degradation 7, 41 (1999).

15. Vercammen, K., Glaus, M. A., Van Loon, L. R.: Evidence for the existence of complexes between Th(IV) and $\alpha$-isosaccharinic acid under alkaline conditions. Radiochim. Acta 87, 221 (1999).

16. Vercammen, K., Glaus, M. A., Van Loon, L. R.: Complexation of $\mathrm{Th}(\mathrm{IV})$ and $\mathrm{Eu}(\mathrm{III})$ by $\alpha$-isosaccharinic acid under alkaline conditions. Radiochim. Acta 89, 393 (2001).

17. Sarott, F.-A., Bradbury, M. H., Pandolfo, P., Spieler, P.: Diffusion and adsorption studies on hardened cement paste and the effect of carbonation on diffusion rates. Cem. Concr. Res. 22, 439 (1992).

18. Berner, U. R.: A thermodynamic description of the evolution of porewater chemistry and uranium speciation during the degradation of cement. PSI Bericht 90-62, Paul Scherrer Institut, Villigen, Switzerland (1990), and NTB 90-12, Nagra, Wettingen, Switzerland (1990).

19. Wieland, E., Tits, J., Spieler, P., Dobler, J. P., Scheidegger, A. M.: Uptake of nickel and strontium by a sulphate-resisting Portland cement. In: Applied Mineralogy (Rammlmair, D., Mederer, J., Oberthür, Th., Heimann, R. B., Pentinghaus, H., eds.) Balkema, Rotterdam (2000) pp. 705-708.

20. Dyrssen, D.: The preparation of carrier-free Thorium234 (UX1) by ion exchange. Sv. Kem. T. 62, 153 (1950).

21. Vercammen, K., Glaus, M. A., Van Loon, L. R.: Complexation of calcium by $\alpha$-isosaccharinic acid under alkaline conditions. Acta Chem. Scan. 53, 241 (1999).

22. Van Loon, L. R., Glaus, M. A., Stallone, S., Laube, A.: Sorption of isosaccharinic acid, a cellulose degradation product, on cement. Environ. Sci. Technol. 31, 1243 (1997).

23. Van Loon, L. R., Glaus, M. A.: Experimental and theoretical studies on alkaline degradation of cellulose and its impact on the sorption of radionuclides. PSI Bericht 98-07, Paul Scherrer Institut, Villigen, Switzerland (1998), and NTB 97-04, Nagra, Wettingen, Switzerland (1998).

24. Van Loon, L. R., Glaus, M. A., Vercammen, K.: Solubility products of Ca-isosaccharinate and Ca-gluconate. Acta Chem. Scand. 53, 235 (1999). 
25. Tits, J., Bradbury, M. H., Wieland, E., Mantovani, M.: The uptake of $\mathrm{Cs}, \mathrm{Sr}, \mathrm{Ni}, \mathrm{Eu}$ and $\mathrm{Th}$ by $\mathrm{CSH}$ phases under high $\mathrm{pH}$ cement porewater conditions. PSI Internal Report TM-44-98-01, Paul Scherrer Institut, Villigen, Switzerland (1998).

26. Hummel, W., Berner, U., Curti, E., Pearson, F. J., Thoenen, T.: Nagra/PSI chemical thermodynamic data base 01/01. Nagra Technical Report NTB 02-16, Nagra Wettingen, Switzerland, and Universal Publishers/uPublish.com, Parkland Florida, USA, ISBN 1581126204 (2002).

27. Wieland, E., van Loon, L. R.: Near-field sorption database for performance assessment of a ILW repository in Opalinus clay and crystalline host rock. PSI Bericht, Paul Scherrer Institut, Villigen, Switzerland, and Nagra Technical Report NTB, Nagra, Wettingen, Switzerland (in review). 